Although it is idle to speculate without the evidence of blood-sugar estimations carried out in an actual attack, it is unlikely that a cerebral lesion-of the hypothalamus, for example-had caused temporary hypoglycaemia in these cases. Such a lesion, if it were to produce hypoglycaemia, would almost certainly also produce intolerance to insulin, which was not present in our cases. Confirmation of this statement is obtained from a study of the work of Cleveland and Davis (1936), who found insulin intolerance in 12 out of 14 cats with artificially produced hypothalamic lesions.

From those cases in which the syndrome of periodic somnolence and morbid hunger is preceded by an acute infection it is tempting to suggest that some form of mild encephalitis occurs which causes instability of the higher cerebral centres. The syndrome, however, does not appear to be related in any way to epidemic encephalitis. Narcolepsy-a much commoner cause of pathological sleepdiffers from the present syndrome in many important features: (1) the attacks of sleep are shorter and more frequent, being paroxysmal rather than periodic ; (2) excessive hunger does not typically occur ; (3) cataplexy is a characteristic concomitant; and (4) disordered nocturnal sleep is usually present. It is not clear whether the hallucinations described in the Kleine-Levin syndrome are similar to the hypnagogic hallucinations of narcolepsy.

The result of electro-encephalography in Case I cannot be taken as conclusive evidence that a frontal lesion is responsible for the symptoms. (So far as we know, this is the only patient with the disorder to be examined by this means.) If subsequent cases also produce similar results this will be of considerable interest. The result obtained was similar to those found in cases of epilepsy or in patients with an epileptic predisposition who have never had fits. A finding of this sort probably indicates the existence of a cerebral dysrhythmia and nothing more.

\section{Summary and Conclusions}

The syndrome of periodic somnolence and morbid hunger is described, with special reference to the work of Levin.

Two cases are reported which have recently been observed in Royal Naval hospitals, in one of which there was an abnormal electro-encephalographic reading.

These cases, in our opinion, give strong evidence that such a syndrome exists as a definite entity.

Levin's views as to the cause of the syndrome are discussed, but it is considered that the nature of the pathological process is still obscure.

The differential diagnosis is considered with special reference to hypoglycaemia.

For permission to quote these two cases we are indebted to the Surgeon Rear-Admirals at the naval hospitals concerned.

$$
\text { REFERENCES }
$$

Cleveland, D., and Davis, L. (1936). Brain, 59, 459.

Fraser, R., Maclay, W. S., and Mann, S. A. (1938). Ouart. J. Med., n.s., 7, 115. Albright, F., and Smith, P. H. (1941). J. clin. Endocrinol., 1, 297.

Fulton, J. F. (1934). J. Mich. State med. Soc., 33, 175.

Kleine, W. (1925). Mschr. Psychiat. Neurol., 537, 285.

Levin, M. (1929). Arch. Neurol. Psychiat., 22, 1172.

- (1936). Brain, 59, 494.

(1938). J. nerv. ment. Dis., 68, 414

Mettler, F. A., et al. (1936). Arch. Surg., 32, 618

Wilder, R. M. (1940). Clinical Diabetes Mellitus and Hyperinsulinism, Saunders, Philadelphia.

T. Brander (Nordisk Med., 1941, 8, 2547) records two fatal cases of varicella in children aged 2 months and 1 year respectively, who developed the eruption during convalescence from double pneumonia and were living under unfavourable sanitary conditions. One had a scarlatiniform eruption at the onset of the disease and the other had haemorrhages in the pocks. The varicellar lesions soon became necrotic and the subjacent muscle was invaded. Death from septicaemia ensued on the twenty-fifth and seventh days of disease respectively.

\section{HEAVY PERCAINE SPINAL ANAESTHESIA EXPERIENCE GAINED IN A SERIES OF 420 CASES}

\author{
BY $^{\circ}$
}

WILLIAM W. MUSHIN, M.B., B.S., D.A.

Honorary Anaesthetist, Seamen's Hospital, Greenwich, and Central London Throat, Nose and Ear Hospital; Anaesthetist, Royal Dental Hospital; Anaesthetist, E.M.S.

Hypobaric, or light, solutions for spinal anaesthesia are losing their erstwhile popularity. Such techniques as those of Howard Jones (1930), Etherington Wilson (1935), and Lake (1938), though excellent in expert hands, are complex, and failure easily results if details are neglected. To-day, heavy, or hyperbaric, solutions are being increasingly used, by virtue of their simplicity of technique, constancy of result, and safety.

This paper records the experience gained in a personal series of 420 cases over a period of three and a half years, in which heavy percaine ( 1 in 200 , in $6 \%$ glucose) was used, with no deaths and few complications. The technique evolved, though based on that described by Silverton (1934), differs from it in certain respects. The greater part of this work was carried out at the Seamen's Hospital, where the patients were men of excellent physique in whom the production of muscular relaxation by the use of general anaesthesia would have been a problem. It is one of my purposes to point out that it is particularly in such " good risk" cases that spinal anaesthesia produces its most gratifying results.

\section{Behaviour of Heavy Solutions in the Subarachnoid Space}

Solutions heavier than cerebrospinal fluid reaching the cephalic side of the lumbo-sacral projection tend, in the supine patient, to gravitate towards the mid-thoracic region. The number of nerve segments affected when a small volume of solution is introduced (1 to $2 \mathrm{c.cm}$.) depends chiefly on the quantity of drug, because as the solution moves towards the upper dorsal region the drug is being removed from the C.S.F. by both the nerve roots and the blood stream. In any case, it-will not travel further than the lowest part of the dorsal curve unless there is still unabsorbed drug left at this point and the patient is steeply tilted head down. Thus sensory loss tends to stop automatically at about the level of D 6 to D 7 (ensiform), with motor loss one or two segments below this because posterior root effect is predominant when the solution stays in the dependent part of the thecal space. Thus two safety factors are inherent in the use of heavy solutions: the dorsal curve, limiting upward spread in the supine patient, and gravity, which limits anterior root involvement, with consequent less intercostal and sympathetic paralysis. If the patient is sitting up, a heavy solution sinks to the lowest part of the thecal sac, affecting the sacral roots only. There are thus two levels of anaesthesia, which automatically adjust themselves: one to the ensiform, suitable for lower abdominal surgery; the other to the "saddle" area, suitable for perineal operations.

\section{Objections to Heavy Solutions Answered}

Objections (e.g., Lake, 1938) to heavy solutions have been the "lack of control," and the danger of using the Trendelenburg position early in the operation.

"Lack of Control."-This suggests that the anaesthesia may ascend too high; but the difficulty I have experienced with heavy percaine has been to get the solution to ascend higher than D 6 to D 8 by gravity alone. For upper abdominal anaesthesia ip has had to be supplemented with barbotage (or mixing with C.S.F.). The only control between the limits of 
the sacral area and the ensiform which I have found desirable has been to restrict the anaesthesia to the legs.' The lower half of the body can be divided into four zones, and anaesthesia limited to each: (a) the upper and lower abdomen, D 5 to L 3 ; (b) the lower abdomen, D 7 to $\mathrm{L} 3 ;(c)$ the legs, L 1 to $\mathrm{S} 2$; and $(d)$ the perineum, $S 1$ to $S 3$. No more control than this has been found desirable, and no more is possible with hypobaric solutions, with the exception of the Wilson time-diffusion method.

The Trendelenburg Position Early in the Operation.The myth of medullary paralysis has been dispelled by Sebrechts (1934). The real danger of cephalic spread is phrenic palsy superadded to a progressive intercostal paralysis. It is admittedly difficult to disprove the objection to the Trendelenburgeposition early in the operation. It has been shown (Koster et al., 1936; Hirschfelder and Bieter, 1932) that in the time taken to prepare the patient for the surgeon (ten minutes) the concentration of novocain (in heavy solution) in the C.S.F. has been so reduced by absorption into the blood stream (which Howard Jones said is only less rapid than intravenous injection) and by nerve-root fixation that no alteration in motor loss and very little in sensory loss can be obtained after this time. Observations made in this series on the development and extent of andesthesia in relation to time have led me to conclude that heavy percaine behaves in a similar manner. In common with Macintosh (personal communication), Evans (1941), and others, I have on numerous occasions in this series placed patients in a slight head-down tilt for abdominal anaesthesia with no ill effect. That no harm results from this depends on the correct dose being used, so that most of the percaine is removed from the C.S.F. before it reaches the upper dorsal region.

\section{Solution Used}

The solution employed in this series was 1 in 200 percaine in $6 \%$ glucose, and is very nearly isotonic. Its specific gravity is 1024 , compared with 1007 for C.S.F., and it is thus strongly hyperbaric. Percaine is now well known as a powerful drug whose action is long-lasting (two to three hours). This solution of percaine, first described by Silverton (1934) and recently by Frankis Evans (1941), enables the drug to be used according to the simple, well-tried, and proved principles of gravity control laid down by Barker (1907).

As with any form of spinal anaesthesia, safety in this series was ensured by attention to the following points: (1) pre-operative preparation and medication; (2) avoidance of this form of nerve block in certain patients ; (3) a careful and constant technique; (4) constant vigilance in the theatre, so that possible complications may be forestalled; and (5) post-operative treatment.

Pre-operative and post-operative treatment are now so well known that only a few personal comments will be made. The technique in the theatre will be described in detail.

\section{Pre-operative Treatment}

It is a good maxim that " the twenty-four hours before an operation is not the best time to alter the habits of a lifetime." At the preliminary visit no mention is made of spinal anaesthesia, as the public generally is not sufficiently educated in this matter and ignorance may engender fear. The usual pre-operative medication for adults is omnopon grain $1 / 3$ and scopolamine grain $1 / 150$, the amount being reduced proportionately for the young and the aged. The confident patient needs no more than this, and by avoiding larger doses of respiratory depressants (among other things) I have been rewarded by few pulmonary complications.

\section{Contraindications to Spinal Anaesthesia}

I regard spinal anaesthesia essentially as expedient for those who are good risks for any form of anaesthesia. The more robust the patient the more suitable he is for spinal anaesthesia. It is never used for ill, dEB̈rlitated, or shocked patients. Some other form of regional block, or inhalation anaesthesia, is chosen for these. For major surgery below the umbilicus in "good risk" subjects I regard spinal anaesthesia as the method of choice, general anaesthesia being used only when spinal anaesthesia cannot, rather than the reverse. A number of patients, however, express a wish-always respected-to be asleep during the operation. If no great muscular relaxation is desired by the surgeon, inhalation or intravenous anaesthesia is used ; but if relaxation is an essential requirement, then spinal anaesthesia is induced after the patient has been put to sleep. Whenever supplementary general anaesthesia was required in this series cyclopropane was employed. This gas is particularly suitable for the purpose, since a mixture rich in oxygen is given, and the closed circuit, with $\mathrm{CO}$. absorption, reduces the respiratory excursions.

\section{Technique \\ (A) Vasopressor Drug}

A vasopressor is used to help maintain a good coronary circulation rather than a good medullary blood supply. The latter is taken care of by the adoption, if necessary; of the Trendelenburg position. No vasopressor is needed when the anaesthesia is below the mid-lumbar region, as no vasomotor sympathetic fibres are given off lower than this level. Though employment of ephedrine is a standard current practice in spinal anaesthesia, a mass of evidence has accumulated which indicates that it may be, and often is, harmful. I propose to discuss this fully in another paper, and will merely say here that I have not used it for the past three years, but have substituted phedracin (Ciba 2020) (Jones and Wilson, 1938), a synthetic, peripherally acting, sympathetic stimulant, whose main difference from ephedrine is that it does not produce tachycardia. Like all vasopressors it only helps to counteract the fall of blood pressure, and faith should be placed in the Trendelenburg position rather than in drugs. In the greater part of this series, patients received 0.2 gramme of phedracin intramuscularly, just before the lumbar puncture, if the spinal anaesthesia was to extend above the mid-lumbar region. A few minutes after the administration of phedracin the patient usually shows marked "goose-skin" and often feels shivery. Since this drug has been used in this series and in spinal anaesthesias by other methods, no case of collapse has occurred and nausea has become a rarity. The patients keep a good colour. Phedracin has been repeated during the operation in a dosage of 0.1 gramme intravenously in a case in which a rapid effect was desired, and, unlike ephedrine, its effect was almost as great as that of the initial dose.

\section{(B) Lumbar Puncture}

Position of Patient.-For perineal anaesthesia, lumbar puncture is performed with the patient sitting up, with knees flexed and hands clasping ankles, aptly described by Maxson (1938) as the "sitting bull" position; otherwise the puncture is always performed with the patient on his side. If the incision is unilateral, as it so often is-e.g., herniotomy, appendicectomy, leg operation-the patient lies on the affected side, so that the most intense anaesthesia is in that part. The following three instructions to the patient, given in this order, have been found useful in positioning him quickly and without fuss-e.g., for a left-sided operation: (i) "Lie on your left side with hip and shoulder along the back edge of the table"; (ii) "Bend your knees so that your thighs touch your abdomen"; (iii) "Tuck your head down towards your knees."

Skin Puncture.-The third lumbar interspace is always chosen, but if this is diffiçult the one above is used. No local anaesthetic is necessary if a sharp primary-puncture 
needle is employed and hair follicles are avoided. The puncture needle makes a small triangular hole for the spinal needle and obviates strain or bending of the latter.

Spinal Needle.-My own choice is the Pitkin or Pannett needle (22 S.W.G.). Two needles, 3 in. and $3 \frac{3}{4}$ in:, are always ready on the tray, the latter for fat or muscular people. Loss of C.S.F. is scrupulously avoided throughout the procedure. The method by which the spinal needle is held and inserted, avoiding both damage and contamination of the shaft, is as follows. The anaesthetist bends his body so that his shoulders are parallel with those of the patient and he is looking towards the patient's head. The needle is .held with the hilt between the thumb and first fingers of each hand, the little fingers resting on the patient's back. By this means the needle can be aimed accurately and the slightest deviation from its mid-line course can be detected. No strain is put on the needle, and its shaft is never touched with the fingers.

Injection of Percaine.-It is important that the syringes and needles be sterilized by boiling in distilled water to avoid precipitation of the percaine, which occurs in the presence of alkali. If the solution becomes cloudy in the syringe it should be discarded. The syringe is emptied

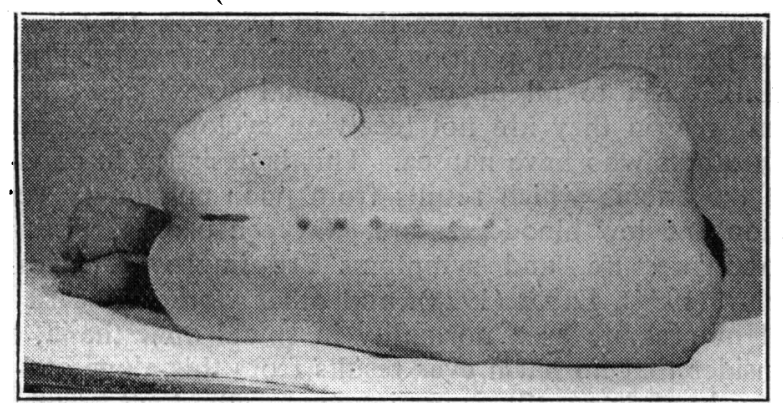

FIG. 1.-Snowing how table may have to be tilted to produce a horizontal spine when the patient has broad shoulders.

at such a rate that the dose is injected in about fifteen seconds (i.e., a little slower than a hypodermic injection). A few drops of C.S.F. are always aspirated at the start to be quite certain that the needle is well in the subarachnoid space. Unless this certainty is always present before injection failures will occur. Air bubbles in the syringe are scrupulously avoided and are never injected into the C.S.F. When all the solution has been injected the needle, with the syringe attached, is left in situ for about half a minute to allow the local increase in pressure to subside and thus avoid leakage of percaine at the dural puncture.

Inclination of Spinal Column during Injection.-The inclination of the spinal column. rather than of the table influences the flow of the percaine solution. It is obvious that a patient with broad shoulders and narrow hips lying on his side may have a horizontal spinal column although the table is tilted head down (see Fig. 1). During the injection the line of spines between the point of injection and the lower thoracic region is kept horizontal for lumbar anaesthesia (i.e., the legs), but with a slight head-down tilt for abdominal anaesthesia.

Dosage.-After experiment, using Silverton's figures as a basis, the following dosage was arrived at. (These doses should be regarded as maximal, and with experience can be reduced according to the size and condition of the patient.) (1) Perineal or saddle anaesthesia, $1 \mathrm{c.cm}$. ; (2) anaesthesia of the legs (to L 1), $1.5 \mathrm{c.cm}$.; (3) anaesthesia of the lower abdomen, $1.8 \mathrm{c.cm}$.; (4) anaesthesia to the nipples, 2 c.cm. and $11^{b} \mathrm{c.cm}$. of barbotage.

Posture after Injection of Percaine-The technique we adopt with regard to posture after injection is as follows:
Perineal Anaesthesia.-The patient is kept sitting up for three to five minutes, so that the heavy solution gravitates to the sacral theca. At the end of this time he is allowed to recline with his head and shoulders elevated. The anaesthesia is sharply limited to the "saddle area " (S1-2 down), with tingling or numbness of the soles of the feet, and the field of anaesthesia is adequate for

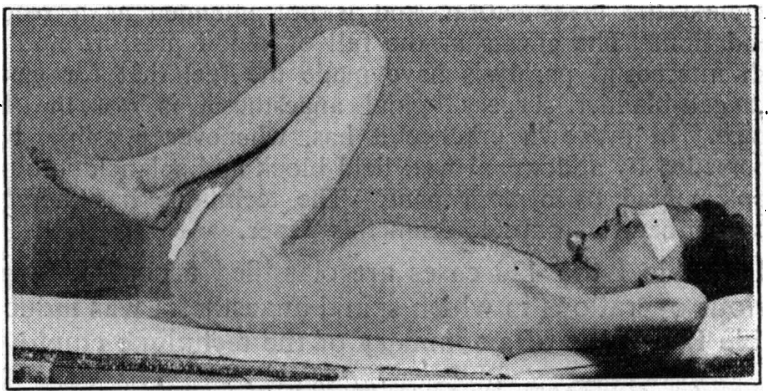

FIG. 2.-Position of patient for production of abdominal anaes-

thesia : flexion of thighs, producing straight lumbar spine:

perineal and ano-rectal operations. As Frankis Evans has rightly pointed out, the nursing staff should be warned of this to avoid burning the soles of the feet with hot-water bottles. No fall of blood pressure or untoward symptoms of any sort have been observed in these cases.

Legs.-For unilateral operations the patient is kept on his affected side for three to five minutes with the spine horizontal. The solution spreads over several segments on both sides of the site of injection. If the spine is not kept quite horizontal either the upper lumbar or the lower sacral nerves may escape and the area of anaesthesia be insufficient. It must be admitted that the production of complete anaesthesia of both lower limbs proved the greatest problem with this heavy solution of percaine. After much experiment and many failures it was found that bilateral anaesthesia from $L 1$ down was inconstant unless $0.5 \mathrm{c.cm}$. of barbotage with C.S.F. was given. The patient is immediately turned on to his back after the injection, with the table horizontal and his thighs flexed on to his abdomen to produce a straight lumbar spine. This position is maintained for three to five minutes or until the legs waver or fall.

Lower Abdomen.-For unilateral opera- . tions such as herniotomy the spine is kept tilted after the injection in a slightly headdown position (about 5 degrees) and the patient remains on the affected side for three to five minutes. He is then turned on his back, and if the anaesthesia is adequate the table is levelled. If the anaesthesia has not yet reached the umbilicus the table is left in a 5-degree Trendelenburg position, and the anaesthesia will surely be complete in a few minutes. When the operation is inside the lower abdomen the patient is turned on to his back immediately after the injection and the table kept tilted in a 5-degree Trendelenburg position. The patient flexes his thighs on to his abdomen and keeps like this for three to five minutes or until his legs fall of their own accord (see Fig. 2). The table is left with this tilt, and the sensory loss will be found to ascend gradually to about the ensiform and no higher, as already explained. In about half the patients undergoing hernia and lower abdominal operations the anaesthesia was found to extend no lower than the knees or even mid-thigh, and such a typical distribution is shown in Fig. 3.

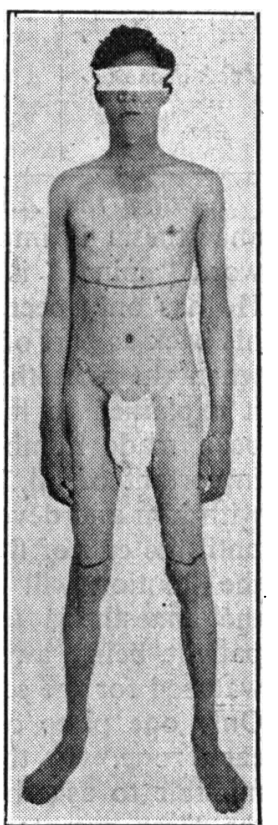

Fig. 3.- Showing a typical segmental distribution of anaesthesia for a lower abdominal operation (D 7 - L 3).
These patients were able to move their feet and ankles and often their knees, and had varying degrees of şensation in the legs, from numbness to fully normal. This localized effect has in faet made me regard heavy percaine as unsuitable for operations which involve both the perineum, or legs, and the abdomen. Sensation and movement in the legs, therefore, should not be taken as an indication of failure. I regard this phenomenon as one of the best 
features of this solution of percaine, as the absence of muscular and vasomotor paralysis in the legs cannot but $\mathrm{be}$ 'beneficial to the patient. Those who could move their legs were invariably of good colour and had no untoward symptoms throughout the operation.

Upper Abdomen.-Although upper abdominal anaesthesia was produced in 37 patients in this series, this was done to complete the investigation, and is not intended as a recommendation. The effects of the fall of blood pressure and the high intercostal paralysis have made me feel that for gastric and gall-bladdet surgery spinal anaesthesia is not the best choice. In my own practice it has, whenever possible, been superseded by abdominal wall field block and splanchnic block, supplemented by cyclopropane. The technique has therefore been deliberatel omitted from this paper.

In Table I the 420 cases are classified according to the various operations in which spinal anaesthesia was induced. Table II consists of a summary of the technique employed.

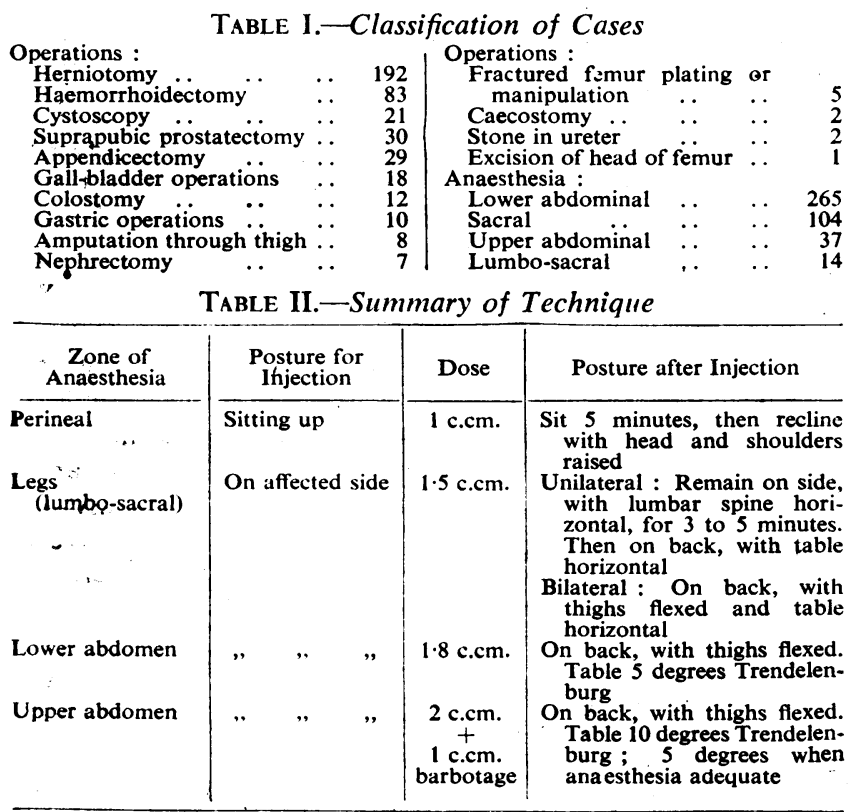

Testing the Anaesthesia.-The manner of testing the anaesthesia is important. Until this moment is over the word "spinal" is not mentioned in the patient's hearing. He has only been told that he is to have an injection in his back as part of the preparation for the operation. Only when the anaesthesia has developed and is satisfactory is it explained to him that the part to be operated on has been made numb and that he will feel no pain. Most important of all, he is told that the anaesthetist will stay with him and devote his entire attention to his needs. Not until the end of five minutes after injection, by which time the solution will have gravitated to the required level, is the anaesthesia tested with towel forceps. Without the patient being aware of what is being done, his face is watched for the screwing up or the frown that means pain. Only one piece of skin is pinched at a definite spot for each zone. In the case of lumbar anaesthesia it is permissible to ask the patient if his legs are feeling warmthe first symptom to appear. Very soon afterwards tingling is felt, and it is then certain that satisfactory anaesthesia will develop. Flexion of the thighs in the production of abdominal anaesthesia has the effect of straightening the lumbar spine (see Fig. 2) and preventing the accumulation of percaine on the sacral side of the lumbo-sacral projection. Admirable diagrams showing the effect of this curve in. splitting the dose of a hyperbaric solution when flexion is not done have been given by Vehrs (1935). In this series I have taken, and recommend whole-heartedly, his advice to use, whenever possible, the lateral position to determine the height of anaesthesia, since in this position the variable factors of the spinal curves are eliminated.

\section{Constant Vigilance in Theatre}

Once anaesthesia has developed, the anaesthetist maintains an unbroken vigilance for the signs that betoken the onset of the rare complications of a harmful fall in blood pressure or of cardio-respiratory failure. Blood-pressure readings are not taken on conscious patients, and, even with those asleep with cyclopropane, élinical observation is considered the more reliable guide. Changes of posture, if necessary at any time during the patient's stay in the theatre, are made very gradually, and"the literature abounds with stories of collapse occurring when the patient was quickly tilted or turned. Fall of blood pressure is denoted by a gradual onset of pallor and, when phedracin is used, coincident slowing of the pulse. This does not cause alarm so long as the normal pulse/B.P. ratio is maintained. The patient complains of nausea or may retch. Only when the pulse rate begins to rise, and particularly when it approaches or exceeds the systolic blood pressure, is concern felt. If definite signs of falling blood pressure are present, or, if it is being recorded, when it falls below $100 \mathrm{~mm}$., the table is tilted about 10 degrees head down. It is now my practice, in addition to adopting the Trendelenburg position, to administer oxygen by a B.L.B. mask to all upper abdominal spinal cases if for some reason they are not receiving cyclopropane, and to any others who have nausea. This is designed to counteract the anoxia which results from poor pulmonary ventilation and low blood pressure. Oxygen usually raises the blood pressure, and symptoms are improved. Koster, Vehrs (1934), Labat (1928), and other workers regard the fall in pressure as a normality in spinal anaesthesia, and consider that no harm ever results from this alone so long as a head-down tilt is maintained. By this means an adequate supply of blood to the medulla is ensured by gravity, and filling of the heart is helped. In addition to the use of the head-down position and of oxygen, which is the main line of treatment, 0.1 gramme of phedracin is given hypodermically or, with caution, intravenously. Seevers and Waters (1932) showed that a great factor in the production of the falling blood pressure was the intercostal paralysis with which it runs parallel. Large doses of respiratory depressants like morphine and the barbiturates are avoided before spinal anaesthesias which are to involve the thoracic nerves. The Trendelenburg position tends to raise the blood pressure but cannot. affect the respiratory volume as the thorax is already immobilized (Lewis and Palser, 1938).

Nausea and vomiting were the most frequently observed complications in the theatre. In this series nausea occurred in $12(2.8 \%)$ cases, but was transient in all instances and soon passed when the patient was tilted head down: all these attacks came on about fifteen to twenty minutes after the injection. Nausea may be due to a combination of one or more factors such as fear, the fall of blood pressure, the effect of percaine on the vomiting centre via the blood stream (Howard Jones, 1932 ; CoTui, 1934), anoxaemia, and traction on viscera whose nerve supply has not been blocked, such as the stomach when anaesthesia extends to the xiphisternum (Youngblood, 1939). Fortunately, retching appears to have a stimulating effect, and patients are usually brighter and better after it. Retching occurred in 5 cases $(1 \%)$, and in one in which it did not stop quickly an intravenous injection of 0.05 gramme of phedracin brought about an immediate cessation.

Collapse occurred in only bne of our cases, and was due to'sudden change of pesture at the end of a long operation. A steep Trendelenburg position and oxygen under 
pressure promoted rapid recovery. Respiratory failure due to phrenic palsy was not seen, and in fact had not occurred in my experience with spinal anaesthesia. Phrenic involvement or collapse with respiratory arrest indicates immediate artificial respiration. If means of oxygen inflation of the lungs is not to hand I would recommend a method of artificial respiration, now fallen into disuse, which I have often successfully employed in general anaesthesia. This is mouth-to-mouth respiration via an ordinary face-piece with a gauze swab as filter.

\section{Post-operative Treatment}

Towards the end of the operation the following instructions are given to the patient, if he is awake, as well as explained to his nurse: "During the next twenty-four hours you should drink as much as you can [this if the operation permits], you must not lift your head from your pillow, and you must not smoke or read." I have been led to the conclusion that blocking the foot of the bed is not of such importance in preventing headache as using a fine needle, rigid asepsis, and avoiding loss of C.S.F. In those patients in whom the development of a post-operative pulmonary complication is likely because of the operation or pre-existing disease, the bed is never blocked, and the patient is sat up as soon as possible. It is our observation that such patients rarely complain of headache, and a typical severe "spinal" headache has not occurred in them in my experience. The average patient has 6-inch blocks under the foot of the bed for six hours, and then is allowed one small pillow, but he does not raise his head for twentyfour hours. Abstention from smoking during the first few days removes what may be the cause of a post-operative bronchitis. A high fluid intake attempts to maintain a hydraemia and helps in the prevention of headache. Food is allowed when the patient feels the need for it, as this is a sure guide to alimentary function.

\section{Post-operative Complications}

In spite of the care taken over lumbar puncture 30 (7.1\%) patients complained of headache (Table III) when asked, but without a leading question many headaches TABLE III.-Complications

\begin{tabular}{|c|c|c|c|c|c|}
\hline & $\begin{array}{c}\text { Upper } \\
\text { Abdominal }\end{array}$ & $\begin{array}{c}\text { Lower } \\
\text { Abdominal }\end{array}$ & $\begin{array}{c}\text { Lumbo- } \\
\text { sacral }\end{array}$ & Sacral & Total \\
\hline $\begin{array}{l}\text { Headache } \\
\text { Nausea in theatre ... }\end{array}$ & $\begin{array}{l}1 \\
8\end{array}$ & $\begin{array}{l}8 \\
4\end{array}$ & 1 & - & $30(7 \cdot 1 \%)$ \\
\hline $\begin{array}{l}\text { Vomiting } \quad \text { " } \\
\text { Chests : }\end{array}$ & 3 & 2 & - & $=$ & $5(1 \cdot 1 \%)$ \\
\hline $\begin{array}{l}\text { (i) Mild cough } \\
\text { (ii) Collapse of }\end{array}$ & 1 & 8 & 1 & - & $10(2.4 \%)$ \\
\hline Acute retention of & 2 & - & - & - & $2(0 \cdot 5 \%)$ \\
\hline $\begin{array}{c}\text { urine } \\
\text { Residual areas of }\end{array}$ & - & 1 & 2 & 2 & $5(1 \cdot 1 \%)$ \\
\hline $\begin{array}{l}\text { anaesthesia } \\
\text { Collapse in theatre }\end{array}$ & $\overline{1}$ & $\stackrel{3}{-}$ & $\underline{2}$ & $\underline{4}$ & $\begin{array}{l}9(2 \cdot 1 \%) \\
1(0.2 \%)\end{array}$ \\
\hline
\end{tabular}

would have gone uniecorded. Headaches after spinal anaesthesia have always received more prominence than those after general anaesthesia. But Baird (1932) found that, following abdominal operations, headaches occurred with the same frequency after both forms of anaesthesia, while with perineal operations $13 \%$ had headaches after general compared with $2 \%$ after spinal anaesthesia. Of the 30 patients with headache, 26 received no treatment other than aspirin, their cases being characterized by mildness, low diastolic pressure, and an increased intensity when the head was raised. The remaining 4 were more severe. In 2 of these $0.5 \mathrm{c.cm}$. of pituitrin cured the headache rapidly. The third had $20 \mathrm{c.cm}$. of $20 \%$ glucose intravenously and $0.5 \mathrm{c.cm}$. of pituitrin (repeated once), and the headache : gradually passed off in two days. The fourth had a particularly, intense headache, relieved on sitting up. Lumbar puncture, revealed C.S.F, under pressure, withdrawal of which cured the headache.
Pulmonany, Complications.-After long and extensive abdominal operations patients are sat up and encouraged to perform previously learned breathing exercises. This is also done in any other cases in which it is thought likely that lung complications might ensue. Ten cases $(2.4 \%)$ developed a mild bronchitis, but in 7 of these, all hernias, a "slight cough" was present before the operation. Two cases in addition developed basal collapse, one after a difficult gastrectomy, and the other after cholecystectomy. The possibility of post-spinal headache has never been allowed to influence prophylactic treatment: of lung complications.

Acute Retention of Urine.-This complication, so often seen when stovaine is used, occurred in only 5 cases. All responded to an injection of doryl. From experience gained with stovaine, doryl is given as soon as retention is diagnosed, without trying other measures. In view of the rarity of the complication in this series, it is interesting to note that ephedrine can cause acute retention (Balyeat and Rinkel, 1932 ; Valentine and Fitzgerald, 1935).

Residual Patches of Anaesthesia.-In 9 patients (2.1\%) small scattered areas of numbness persisted in the legs, feet, or perineum for varying periods, but all disappeared by the end of two weeks. This phenomenon was elicited only by careful questioning and examination, and would otherwise have passed undetected.

Late Results.- So far as I am aware there were no late effects due to the spinal anaesthesia. The patients were not followed up, from the anaesthetist's point of view, after leaving hospital, but a great many appeared in the surgical follow-up departments, where any aftereffects due to the spinal anaesthesia would have been reported. During the time that the above series was being collected other spinal anaesthesias were being induced both with light percaine and with novocain. The expert spinal anaesthetist should include many different methods in his armamentarium so that he may choose an agent and a technique suitable for a particular case. In my opinion, for reliable all-round use, with freedom from anxiety and major complications, heavy percaine employed in the way described above has proved the most useful.

\section{Summary}

A series of 420 cases in which spinal anaesthesia was induced with heavy, or hyperbaric, percaine (1 in 200 , in $6 \%$ glucose) forms the basis of this paper.

The technique is simple, safe within the given doses, and the results constant. Few complications occurred and no deaths.

Selection of patients is important, and the method is particularly indicated for " good risk" cases and for such operations as haemorrhoidectomy and herniotomy.

I owe thanks to Mr. Percival P. Cole, senior surgeon at the Seamen's Hospital, for encouragement and patience during this study, and to Prof. R. R. Macintosh and Mr. S. M. Cohen for helpful suggestions.

\section{REFERENCES}

Baird, D. (1932). Glasg. med. J., 118, 217.

Balyeat, R. M., and Rinkel, H. J. (1932). J. Amer. med. Ass., 98, 1545. Barker, A. E. (1907). British Medical Journal, 1, 665. CoTai, F. W. (1934). Anesth. and Analges., 13, 183

Evans, Frankis T. (1941). Proc. roy. Soc. Med. (Anaesth. Sec.), 34, 633.

Hirschfelder, A. D., and Bieter, R. N. (1932). Physiol. Rev., 12, 190.

Jones, F. A., and Wilson, C. (1938). Lancet, 1, 195.

Jones, W. Howard (1930). Brit. J. Anaesth.,' 7, 99.

(1932). Anesth. and Analges., 11, 224.

Koster, H., et al. (1936). Amer. J.' Surg., 33, 245.

Labat, G. (1928). Ibid., 5, 625.

Lake, Norman C. (1938). Lancet, 2, 241

Lewis, D. L., and Palser, E. G. M. (1938). British Medical Journal, 1, 1202.

Maxson, L. H. (1938). Spinal Anesthesia, Philadelphia.

Sebrechts, J. (1934). Brit. J. Anaesth., 12, 4.

Seevers, M. H., and Waters, R. M. (1932). Anesth. and Analges., 11, 85.

Silverton, R. J..(1934). Austral. New Zeal. J. Surg., 3, 223.

Valentine, J. J., and Fitzgerald, J. S. (1935). J. Urol., 34, 314

Vehrs, G. R. (1934). North-West Med., 33, 311.

(1935). West. J. Surg., 43, 16.

Wilson, WoiEtherington (1935). Anesth and Analges., 14, 102:

Youngblood, J. C. (1939). Ibid., 18, 51. 